\title{
Airborne/Droplet Infection Isolation
}

\begin{abstract}
Airborne/droplet infection is caused by infected agents in the air around a person. Microbial pathogenic agents that are mainly transmitted airborne are aerosols, re-aerosols, microbe-carrying particles, huge amounts of bacteria-carrying airborne skin cells, dust, droplets and droplet nuclei. At the same time, there is always a contact transmission from contaminated environment, equipment, textiles and waste. Droplet nuclei are small evaporated droplet residues $(<5 \mu \mathrm{m})$ produced by coughing, sneezing, shouting, singing and speaking very distinctespecially the consonants. Droplet nuclei remain for many hours in the air and may be carried by normal air currents in long distances outside the room. Therefore, "droplet isolation and droplet precaution" is included in the airborne isolation regime. The source of infection is usually a patient but may also be a healthy carrier. The patient should be placed in isolate dedicated for airborne infections.
\end{abstract}

\section{Keywords}

Airborne pathogens $\cdot$ Droplet nuclei $\cdot$ Air and contact isolation $\cdot$ Protection $\cdot$ PPE Healthcare personnel $\cdot$ Control

\subsection{Purpose}

To prevent transmission from an infectious patient to other patients, personnel, visitors and the environment and to protect patients with impaired immune defence against infection [1-8]. 


\subsection{Comprise}

- All patients having contagious disease that can easily be transferred directly or indirectly via contact, blood and body fluids, air/droplets or via equipment, textiles and surfaces.

- All patients with significant reduced infection defence or otherwise infection vulnerable and who should be protected against infection.

\subsection{Responsibility}

Hospital management should ensure necessary capacity and type of isolating units: contact- and air-droplet isolates and protective isolates. Updated isolation routines, adequate protective equipment_-including PPE_routines for disinfection of rooms and surfaces and disinfectants and hand hygiene facilities should be available.

Department management should implement isolation procedures, train the use of PPE, control the use of routines and provide sufficient stock and capacity of PPE and means for disinfection and hand hygiene.

The staff should follow current guidelines for treatment of patients with infections and for patients that should be extra protected against infections.

\subsection{Practical Measures}

There are many guidelines that are discussing airborne infections and definitions and methods to stop the spread by air [1, 2, 9-16]. Air outside houses normally contain a variable load of bacteria, dust and particles, and the number of bacteria may be 40-100 CFU (colony-forming units) per $\mathrm{m}^{3}$ (1000 L) air. Inside rooms where healthy people are present, the number may increase to $300 \mathrm{CFU}$ or more, dependent of number of people and area. In operation rooms, it is recommended not more than $100 \mathrm{CFU} / \mathrm{m}^{3}$ air to reduce risk of postoperative wound infection.

All humans are continuously releasing bacteria and skin cells to the air and environment while moving around and are continuously picking up new microbes from the environment and air. In hospitals, there are many patients with infections (20$30 \%$ of the patients-hospital associated or not) that may spread pathogenic microbes to the air in the patient room or other places [17-20]. About 10-20\% of infections in hospitals and other healthcare institutions are airborne $[9,11,12]$. The transmission may be either directly from a sick patient coughing or sneezing or indirectly via re-aerosols from bedding, cleaning and other activities in the room of a patient with infection $[1,2,9-16,21]$.

The design of isolates for airborne infections is very important to control the spread in the department [22-24]. However, without good knowledge, good routines and the use of personal protective equipment (PPE), no well-designed isolate can stop the spread [2, 9-16, 21-27]. 


\subsubsection{Infections $[3,11,12]$}

- Virus gastroenteritis with vomiting, splashing, aerosol, droplets (noro-, rota-, sapo- and bocaviruses, etc.)

- Respiratory tract viruses (respiratory syncytial virus (RSV), metapneumovirus, bocavirus, parainfluenza viruses, coronavirus, influenza virus, etc.)

- Pandemic influenza

- Whooping cough, measles, rubella and mumps

- Chickenpox or shingles (varicella-zoster virus)

- Herpes simplex in newborns in paediatric and maternity wards

- Systemic infection with meningococci first $24 \mathrm{~h}$ after start of treatment (meningitis, septicaemia). Also evaluated the same way by systemic, severe infection with Haemophilus influenzae, pneumococci and group A streptococci (sepsis, meningitis, necrotizing fasciitis)

- Pneumonia caused by Staphylococcus aureus

- Suspected or known infectious pulmonary tuberculosis

- Ornithosis, tularaemia

- Large, uncontrolled secretion of pus from the wound

- Multidrug-resistant bacteria and MDRO (multidrug-resistant organisms)

- MRSA, methicillin-resistant S. aureus, or vancomycin-resistant MRSA (VRSA). Earlier been infected by MRSA - ever, to disprove infection by negative tests. Exposed to MRSA last 12 months without supervision and monitoring, to disprove infection by negative tests

- Import patient, after contact with healthcare abroad last 12 months

- VRE, vancomycin-resistant enterococci, or multidrug-resistant enterococci (resistance to ampicillin and gentamicin)

- Penicillin-resistant pneumococci (PRP) or multidrug-resistant pneumococci

- Other bacteria that can infect humans via air (multidrug-resistant microbes like Acinetobacter baumannii, Burkholderia cepacia and multidrug-resistant Pseudomonas aeruginosa in the respiratory tract or burns)

\subsubsection{Airborne Infection Isolation Unit [3, 11, 12]}

- Airborne infection isolate with a defined negative air pressure (-16 to $25 \mathrm{~Pa}$ ).

- Alternative is contact isolate with sluice.

- Single room with separate bathroom—entrance from the patient's room—or, if not a bathroom, use of bedpan or urine bottle. This can only be used for a short term until the patient is transferred to an airborne infection isolate and depends on the type of infectious agent.

- Isolate for airborne infections should have a sluice (anteroom), patient room and bathroom with toilet/washstand/shower and a throughput decontaminator/ autoclave.

- Ventilation and pressure. Controlled negative pressure ventilation (-16 to $25 \mathrm{~Pa}$ ) with the lowest negative pressure in the sluice ( -10 to $16 \mathrm{~Pa}$ ), increasing to the 
patient room and further increasing to the highest negative pressure ( -20 to $25 \mathrm{~Pa}$ ) in the bathroom/disinfection room where the room air is exhausted. It is recommended 6-12 air changes per hour. Incoming fresh air comes from the ceiling or high up on the wall of the patient room. Outgoing used air is extracted ca. $15 \mathrm{~cm}$ from the floor (diagonal) or via openings in the lower part of the door to the bathroom/disinfection room. Outgoing, used air is extracted ca $15 \mathrm{~cm}$ from the floor (diagonal) or via openings in the lower part of the door to the bathroom/ disinfection room. From the bathroom/disinfection room, the used air goes via a full decontamination with UVC, through varying filter types, including hepafilters, before entering separate exhaust channels over the roof-far away from incoming air pipes.

- Interlock of doors so that only one open at a time. One of the doors in the sluice must always be closed.

- The sluice must be large enough that a bed can stand there with both doors closed. It must be spacious enough for dressing and undressing of PPE without self-contamination or contamination of the equipment in the sluice. The room must have a sink for handwashing. Throughput cupboards between bathroom and sluice can create ventilation problems and should be completely sealed, and the cabinet doors must be interlocked. Throughput decontaminator or autoclave from the bath to the sluice is an advantage for the disinfection of infection-prone equipment.

- The patient room must be large so that visitors do not come too close to the bed-about $2 \mathrm{~m}$ distance from the bed on the sides and, at the foot end, at least $20 \mathrm{~m}^{2}$. During intensive treatment (respirator, dialysis, monitoring, etc.) and presence of two intensive nurses, there is a need for at least $35 \mathrm{~m}^{2}$ space per patient. The room should have a sink for handwashing and a robust inventory that withstand disinfection with chemicals.

- Decontamination room and bathroom have entrance directly from the patient room, with door that turns into the patient room. The room contains a toilet, shower, throughput decontaminator or autoclave and cabinets for necessary equipment to the patient.

- Direct access from outside. It is an advantage of direct access to the outside of the building via a separate sluice for direct patient in and out.

Well-equipped airborne infection isolates may be used for all types of isolation requirements concerning infectious diseases, including high-risk infections that require strict isolation.

An alternative for a shorter period may be a contact isolate or a single-patient room with sluice (anteroom with handwash) and a separate bathroom with decontaminator.

\subsubsection{The Entrance of the Isolate Is Marked}

When used for patients with airborne infections, a poster with a pink colour (for instance) with information is set up on the entrance to inform the staff about the 
state of the isolate and the use of PPE. Contact hospital infection personnel when needed.

Donning PPE before entering the patient room in this order [11, 12]:

1. Gown is used by everyone-disposable is preferred-with long sleeves and cuffs. The disposable gown is only used once. Multi-use gown is not recommended, but if used, it should be hanged in the patient room (beside the door) with the outside out or-if there is sluice/anteroom-should be inside of the gown hung out. The multi-use gown is changed after each shift or more often when needed and should only be used for a single patient. Waterproof, disposable gowns or disposable plastic aprons are also used if there is spillage/liquid.

2. Cap/hood is used by everyone. It keeps the hair in place and covers the ears. Surgical mask or respirator mask is fastened outside the cap (and then, it is better fastened).

3. Surgical or respirator masks are used by all, fastened on the back of the head and the neck. It should be well fitted over the nose and mouth.

4. Respirator mask with $\mathrm{P} 3$ quality protection is used for:

- Pulmonary tuberculosis, all forms and on suspicion.

- Varicella-zoster, morbilli (measles), pertussis in non-immune person.

- Serious, highly pathogenic, airborne infections-see strict isolation.

- Pandemic influenza.

- Responsible physician decides the use of face masks or respirators.

- Beard prevents sufficient effect of respirators and other face masks.

- Leak test should be done.

5. Face shield/visor/protective eyewear-used in case of splashes, droplets and aerosols with infectious material.

6. Room-bound shoes-by widespread transmission of infection in the room. Room-bound shoes may be heat disinfected in decontaminator after use-or use disposable shoe covers.

7. Gloves-used by all; long cuff that covers the wrist. The use of double gloves may do the work in isolation easier.

Doffing in the sluice or at the exit door if the room has no sluice/anteroom: [11, 12]

Remove PPE in such a way that you do not contaminate yourself or the environment. Doffing is done in a defined area in the sluice on the unclean side. In this order, take off the PPE that you have used:

1. Hand disinfection with gloves on.

2. Room-bound shoes or shoe covers-if used. Room-bound shoes are tilted off and put foot straight into your own shoes. NB! If shoe covers are used, remove them with gloves on.

3. Hand disinfection with gloves on.

4. Gloves: learn the method to take off without recontamination. One is turned inside out when taken off and used as a cloth to remove the second glove. 
5. Hand disinfection.

6. Gown: learn the gown doffing method; open closure on the back (top first), pull the cuffs forward over the hands and gently roll the gown off without touching the outer side of the gown. Gently place the disposable gown in the waste container. Multi-use gowns should be hung in the sluice/anteroom with the inside out. In the case of no sluice, it should be hanged in the patient room at the exit door with the outside out. Change at least for every shift. Disposable gowns are infectious waste; multi-use gowns are infectious textiles.

7. Hand disinfection.

8. Surgical or respirator mask: take back and loosen tape first in the neck and then on the head, and bend the body forward to avoid contact with skin, hair, etc., when taking off the mask.

9. Hand disinfection.

10. Face shield/visor: if used, loosen from behind as a mask.

11. Hand disinfection.

12. Cap/hood: remove from the back as a mask.

13. Disinfect or wash hands.

For textiles, disposable equipment, reusable equipment, crockery/cutlery, waste and sharp objects, see contact isolation.

\subsubsection{X-ray or Other Large Equipment in the Isolate [11, 12]}

All equipment must be disinfected after use. Cover the X-ray cassette with a clean pillow case (or other clean cover) before it is taken into the patient. After X-ray, transfer the cassette to a new, clean pillow case (wipe off with alcohol before the transfer) in distance from the patient, in a cautious way. In the sluice, uncover the cassette carefully and disinfect it completely with $70 \%$ alcohol. Then bring it out in a new pillow case. It is notified about the infection.

Journal trolleys or papers are not taken into isolates. Paper from the isolate that is needed may be put in clean plastic folders before leaving the room for copy (in plastic folder) before the paper is discarded as infectious material. The copy may be submitted to the journal.

Medical Examination/Treatment in Other Departments/Death of the Patient

Provide good advance information on infection risk to relevant departments. Mors is taken care of in the isolate. The requisition is marked in uppercase letters: AIR ISOLATION.

Before transportation to other departments, the patient should be washed and put on new, clean cloth, in a clean bed and with face mask.

$X$-ray examination: Evaluate X-ray examination in the isolate-see above. If examination is done outside the isolation unit, a fully airborne regime is made for the patient. 
Surgical treatment should occur at the end of the daily operation programme, preferably on an operating room particularly suitable for the purpose, with no positive air pressure (preferably negative pressure), without LAF (laminar air filtration) system and with a subsequent decontamination of the room as airborne contamination.

Remember good information to all who are treating/taking care of the patienteven when this occurs in isolation unit—such as physiotherapy, sampling, cleaning and so on.

\subsubsection{Laboratory Tests}

Follow guidelines for contact isolation. Note the remiss with capitals for airborne infection isolation.

Transport of patients outside the isolate is avoided if possible $[11,12]$ :

- Only essential transport is permitted and performed by experienced personnel. The ward's personnel must always accompany the patient. Staff transporting and receiving the patient must receive information about airborne infection regime, in advance, and information concerning adequate precautions during transport, including clothing and the use of cap, surgical mask/respirator, gown and gloves.

- The patient should have clean clothes and clean bed and should wear a surgical/ respirator mask when outside the isolation ward. Avoid transport through other wards. Transport a dead patient in clean bed and clean cover or in body bag.

- When the patient is going home by ambulance before he is free from infection, the ambulance personnel must be informed so that adequate measures are implemented. The ambulance should not have unnecessary equipment. Bed/stretcher and the cabin should be disinfected after use in ambulances.

- Hand hygiene before and after the transport.

\subsubsection{Books}

Follow guidelines for contact isolation.

\subsubsection{Visitors}

- Contact the ward office for information about actual protective measures and hand hygiene.

- Visitors are using the same guidelines for attire as the staff.

- See also other information for visitors. 


\subsubsection{Daily Cleaning $[11,12]$}

Use water, ordinary detergent and clean equipment. Special cleaning and disinfection may be appropriate in certain cases-daily. If there are spills of blood or body fluids, the nursing staff should immediately remove the spills with gloved hands and afterwards disinfect the area with chloramine $5 \%$ or household bleach, or peracetic acid, before cleaning.

After use, disinfect mops, cloths and buckets in decontaminator. Consider disposable equipment such as mops and cloths.

Do not handle the used mops/equipment without gloves/infection gown/masks!

Termination of isolation: $[11,12]$

- After completion of the isolation period, all disposable equipment (including unused) like creams, soaps, bandages, etc. which have remained in the room during isolation is treated as infectious waste. All textiles in the room are treated as infectious and sent for laundry.

- Beddings are carefully packaged (to avoid re-aerosols) and sent as infectious textiles.

- Bed equipment and mattresses which cannot be washed or disinfected in the room are packed, labelled, and sent to disinfection.

- Rooms, fixtures, bed, bathroom and all reusable equipment are disinfected with peracetic acid, chloramine 5\% and household bleach or by other means.

- All handles, buttons, switches, call cord, waterproof mattresses, bed, nightstand, toilet, computer, telephone, TV and other contaminated fixtures and equipment are disinfected.

- Floors, walls (1.80 m up), lighting fixtures in the ceiling and other equipment should be disinfected. It is important to have good cleaning on all surfaces to avoid deposits of dust-bearing microbes.

- The responsible nurse, biochemist or radiographer must inform the cleaning staff about the disinfection area and the disinfectant to be used. After the disinfection, the room and all equipment are washed with soap and water.

- The room is aired $1 \mathrm{~h}$ after cleaning.

- Hydrogen peroxide 5\% dry gas may be appropriate in addition to regular disinfection, especially in rooms with a lot of medical equipment and if problems with regular disinfection. Follow written procedures. Three subsequent disinfection cycles must be performed under control of effect on spore test. It does not work against tubercle bacilli but is otherwise approved against bacteria, viruses and fungi.

\subsubsection{Main Cleaning: Turn Out All the Isolation Units}

Consider the main cleaning of isolates 2-4 times per year, depending on usage and accumulation of microbes and dust. Check the filter effect, air ducts and negative pressure. Contact infection control personnel to be sure that the disinfection is done in a proper manner. 
NB! Good hand hygiene is important! It prevents the spread of infection!

Isolation regimens should not be a hindrance for-but included in-diagnostics and treatment.

\subsection{Background Information}

See Chap. 21.

\section{References}

1. European Parliament and Council Directive 2000/54/EC of 18 September 2000 on the protection of workers from the risks related to exposure to biological agents at work.

2. CDC Draft guideline for isolation precautions in hospital. Federal Register. 1994;59:5555270. and 2004

3. Andersen BM. Handbook of hygiene and infection control in hospitals. Part 1: Microbiology and infection control. Bergen: Fagbokforlaget; 2014.

4. Infectious Disease Act. Law 5 August 1994 no. 55 of protection against infectious diseases.

5. Regulations in infection control in health facilities-hospital infections, established by the Health and Social Affairs July 5, 1996 and July 17, 2005 pursuant to § 4-7 and § 7-11 of the Act on Aug. 5, 1994 no. 55 of protection against infectious diseases.

6. Action plan for infection control in Norwegian hospitals, Health Directorate's Guidance series 2-92. Directorate of Health.

7. Use of isolation to prevent spread of infection i8n hospitals. Health Directorate's Guidance series: Directorate of Health, Oslo; 1988. p. 2-88.

8. Health Personnel Act. Department of Health and Social Affairs. Act 1999-07-02 No. 64; 2001.

9. Andersen BM. Handbook of hygiene and infection control in hospitals. Part 1: Microbiology and infection control. Fagbokforlaget. 2014;

10. CDC draft guideline for preventing the transmission of Mycobacterium tuberculosis in health care facilities. Federal Register. 1994;59:54242-303. and 2004; 69: 33034

11. Andersen BM. Isolation. In: Handbook of hygiene and infection control in hospitals. Ullevål University Hospital 1996, 2003 and 2008. p. 216-48.

12. Andersen BM Isolation- air-borne infection. In Handbook of hygiene and infection control in hospitals. Part 2. Practice and theory. Elefantus Forlag; 2016. p. 137-43.

13. CDC. Management of multidrug-resistant organisms in healthcare settings, 2006. CDC 2006. p. $1-72$.

14. CDC. Prevention of transmission of multidrug resistant organisms 2009. CDC 2009.

15. Siegel JD, Rhinehart E, Jackson M, et al. 2007 Guideline for isolation precautions: preventing transmission of infectious agents in healthcare settings. CDC. 2007;

16. Calfee DP, Salgado CD, Milstone AM, et al. Strategies two prevent methicillin-resistant Staphylococcus aureus transmission and infection in acute care hospitals: 2014 update. Inf Control Hosp Epidemiol. 2014;35:772-96.

17. Andersen BM, Seljordslia B, Hochlin K, Rasch M, Syversen G. A predicted outbreak in an overcrowded, administratively neglected and run-down haemodialysis unit as an offer of "New Public Management" in Norwegian hospitals. J Hosp Admin. 2013;2:15-24.

18. Andersen BM, Lindemann R, Bergh K, Nesheim BI, Syversen G, Solheim N, Laugerud F. Spread of methicillin-resistant Staphylococcus aureus in a neonatal intensive unit associated with understaffing, overcrowding and mixing of patients. J Hosp Infect. 2002;(1):1-7.

19. Andersen BM, Holta Ringertz SH, Petersen Gullord T, Hermansen W, Lelek M, Norman BI, Tilrem Nystad M, Anderson Rød K, Røed RT, Smidesang IJ, Solheim N, Tandberg S, 
Halsnes R, Høystad MW. A three-year survey of nosocomial and community-acquired infections, antibiotic treatment and re-hospitalization in a Norwegian health region. J Hosp Infect. 2000;44:214-23.

20. Andersen BM, Rasch M, Hochlin K, Tollefsen T, Sandvik L. Hospital-acquired infections before and after healthcare reorganization in a tertiary University Hospital in Norway. J Publ Health. 2009;7:1-7.

21. Bourouiba L, Dehandschoewerker E, Bush JWM. Violent expiratory events: on coughing and sneezing. J Fluid Mech. 2014;845:537-63.

22. Marier RL. The design of isolation rooms. Infect Control Hosp Epidemiol. 1996;17:3-4.

23. Walker JT, Hoffman P, Bennett AM, Vos MC, Thomas M, Tomlinson N. Hospital and community acquired infection and the built environment- design and testing of infection control rooms. J Hosp Infect. 2007;65:43-9.

24. Eveillard M, Tramier B, Schmit JL, Lescure FX, Biendo M, Canarelli B, et al. Evaluation of the contribution of isolation precautions in prevention and control of multi-resistant bacteria in a teaching hospital. J Hosp Infect. 2001;47:116-24.

25. Andersen BM, Bergh K, Steinbakk M, Syversen G, Magnæs DH, Bruun JN. A Norwegian nosocomial outbreak of methicillin-resistant Staphylococcus aureus resistant to fusidic acid and susceptible to other anti-staphylococcal agents. J Hosp Infect. 1999;41:123-32.

26. Grub C, Holberg Petersen M, Medbøe S, Andersen BM, Syversen G, Melby KK. A multi-drug resistant, methicillin-susceptible strain of Staphylococcus aureus from a neonatal intensive care unit in Oslo, Norway. Scand J Infect Dis. 2010;42:148-51.

27. Tang JW, Eames In Li Y, et al. Door-opening motion can potentially lead to a transient breakdown in negative-pressure isolation conditions: the importance of vorticity and buoyancy airflows. J Hosp Infect. 2005;61:283-6. 